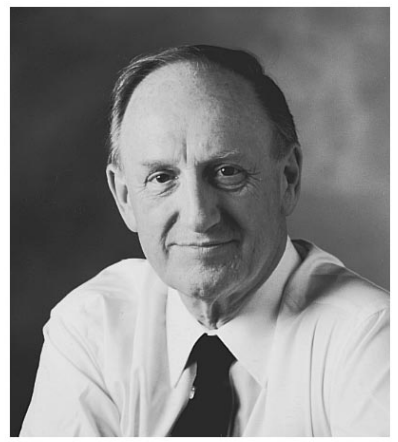

\section{Thank You, Over and Out}

This is my last editorial as your editor. I thank you all for the opportunity that you have afforded me during the last seven years to be your editor. It has been an interesting time for us all in optical science and engineering as the field has developed into a discipline that provides enabling technologies to a wide variety of current and future devices and systems. For me it was a great opportunity to serve this discipline that has been a part of my professional life for well over 40 years. The editorship has brought together two aspects of that life-research and teaching. Research and development results need to be communicated and shared in an authoritative way so that we can all learn of the progress of our collective endeavors and apply those results to our own work no matter where that is in the total spectrum of optical science and engineering. Hence the need for, and the role of, your refereed journal Optical Engineering.

I thank all those who have contributed to the success of the journal; authors, reviewers, guest editors, editorial staff in Bellingham, and perhaps the most important group-the readers. Without that support the editor is nothing! One group that has also been important have been "the correspondents." The feedback and constructive comments and suggestions of this group have been most helpful. Of course, all these groups that have been supportive are individuals who fulfill a variety of roles across the set of groups; authors are reviewers, readers are authors, etc. I am confident that Don O'Shea will receive the same level of support that I have enjoyed as he continues to move the journal forward as the major international journal.

You will have noticed that I used the phrase "the discipline of optical science and engineering." I believe it is a discipline in its own right, but if you don't like that idea then I am sure that you will agree that there is an integrated body of knowledge that constitutes optical sciences and engineering. I have always believed that technology is the embodiment of known science (true in the Stone Age and true today). Engineering is then the integrated use of that known science and technology into devices and systems that can be used to solve current problems and make our world a better and safer place to live in.

So I close by rewriting Ralph Waldo Emerson (with my apology!).

"Good-bye, proud journal! I'm going home:

Thou art my friend, and I am thine,"

Over and Out,

Brian J. Thompson Editor 